\title{
Choroid Plexus Megalin Is Involved in Neuroprotection by Serum Insulin-Like Growth Factor I
}

\author{
Eva Carro, ${ }^{\star}$ Carlos Spuch, ${ }^{\star}$ Jose Luis Trejo, Desiré Antequera, and Ignacio Torres-Aleman \\ Laboratory of Neuroendocrinology, Cajal Institute, Consejo Superior de Investigaciones Científicas, 28002 Madrid, Spain
}

The involvement of circulating insulin-like growth factor I (IGF-I) in the beneficial effects of physical exercise on the brain makes this abundant serum growth factor a physiologically relevant neuroprotective signal. However, the mechanisms underlying neuroprotection by serum IGF-I remain primarily unknown. Among many other neuroprotective actions, IGF-I enhances clearance of brain amyloid $\beta$ $(\mathrm{A} \beta)$ by modulating transport/production of $\mathrm{A} \beta$ carriers at the blood-brain interface in the choroid plexus. We found that physical exercise increases the levels of the choroid plexus endocytic receptor megalin/low-density lipoprotein receptor-related protein-2 (LRP2), a multicargo transporter known to participate in brain uptake of $\mathrm{A} \beta$ carriers. By manipulating choroid plexus megalin levels through viral-directed overexpression and RNA interference, we observed that megalin mediates IGF-I-induced clearance of A $\beta$ and is involved in IGF-I transport into the brain. Through this dual role, megalin participates in the neuroprotective actions of IGF-I including prevention of tau hyperphosphorylation and maintenance of cognitive function in a variety of animal models of cognitive loss. Because we found that in normal aged animals, choroid plexus megalin/LRP2 is decreased, an attenuated IGF-I/megalin input may contribute to increased risk of neurodegeneration, including late-onset Alzheimer's disease.

Key words: megalin-LRP2; insulin-like growth factor I receptor; choroid plexus; amyloidosis; Alzheimer's disease; physical exercise

\section{Introduction}

Increasing evidence points to a physiological role of insulin-like growth factor I (IGF-I), a widely potent neuroprotective hormone, in the adult brain. Because IGF-I is produced locally by brain cells (Bondy and Lee, 1993), it has been considered a classical paracrine growth factor. However, different lines of evidence strongly suggest that blood-borne IGF-I is an important neuro-surveillance factor (Torres-Aleman, 2000). In response to physiological stimuli such as exercise, circulating IGF-I enters into the brain (Carro et al., 2000) and participates in many of the beneficial actions of exercise, including protection against injury (Carro et al., 2001), enhanced hippocampal neurogenesis (Trejo et al., 2001), or increased brain vessel growth (Lopez-Lopez et al., 2004). Serum IGF-I is probably also underlying the beneficial actions of exercise and environmental enrichment (which includes physical exercise) on brain amyloidosis (Adlard et al., 2005; Lazarov et al., 2005), because it also regulates brain amyloid $(\mathrm{A} \beta$ ) levels (Carro et al., 2002) by enhancing $\mathrm{A} \beta$ clearance. In

\footnotetext{
Received July 14, 2005; revised Sept. 2, 2005; accepted 0ct. 2, 2005.

This work was supported by Spanish Ministry of Education and Science Grants SAF2001-1722 and 2004-0446. We thank Dr. D. LeRoith (National Institutes of Health, Bethesda, MD) for his kind gift of the IGF-IR K1003R cDNA and the LID mice, Dr. J. M. Heard (Pasteur Institute, Paris, France) for his kind gift of HIV vectors, Dr. O. Dominguez (Centro Nacional de Investigaciones Oncológicas, Madrid, Spain) for his help in designing the siRNA of megalin, and Dr. M. Larsson (Uppsala University, Uppsala, Sweden) for his gift of the miniMegalin cDNA. We thank Merck Sharp \& Dohme Ltd. and The Mayo Foundation for Medical Education and Research for providing the Tg2576 mouse line and the double-transgenic mice derived from it for use in this study. We also appreciate the invaluable help of $J$. Sancho and M. Garcia.

${ }^{*}$ E.C. and C.S contributed equally to this work.

Correspondence should be addressed to I. Torres-Aleman, Cajal Institute, Consejo Superior de Investigaciones Científicas, Avenida Doctor Arce 37, 28002 Madrid, Spain. E-mail: torres@cajal.csic.es. DOI:10.1523/JNEUROSCI.2909-05.2005

Copyright $\odot 2005$ Society for Neuroscience $\quad 0270-6474 / 05 / 2510884-10 \$ 15.00 / 0$
}

addition, IGF-I protects against amyloid toxicity (Niikura et al., 2001) and influences other Alzheimer's disease (AD) traits, such as the rate of tau phosphorylation in neurons, by inhibiting the tau kinase glycogen synthase kinase-3 (GSK-3) (Hong and Lee, 1997). Indeed, impaired IGF-I/insulin signaling in mouse brain leads to the appearance of hyperphosphorylated tau (Hpf-tau) and cognitive loss (Schubert et al., 2003, 2004), whereas treatment with systemic IGF-I ameliorates amyloidosis and cognitive derangement in mouse models of AD (Carro et al., 2002, 2005a).

Together, these observations prompted us to analyze the processes whereby IGF-I enters into the brain and promotes $\mathrm{A} \beta$ clearance. We have focused on the brain barrier at the choroid plexus epithelium (the best characterized brain barrier is formed by brain vessels), because this specialized structure is involved in exercise-induced brain uptake of serum IGF-I (Carro et al., 2000) and is actively participating in $\mathrm{A} \beta$ clearance (Zlokovic, 2004). The latter process involves megalin [or low-density lipoprotein receptor-related protein-2 (LRP2)], an endocytic receptor expressed in numerous epithelia. Megalin/LRP2 belongs to the LRP family of multicargo receptors, in which LRP1, the best-studied member of the family, has already been implicated in $\mathrm{A} \beta$ clearance and amyloidosis (Deane et al., 2004; Zerbinatti et al., 2004). Megalin/LRP2 also participates in A $\beta$ clearance through the blood-brain barrier and blood-CSF barrier at the choroid plexus (Zlokovic et al., 1996; Hammad et al., 1997). Megalin is involved in the endocytic uptake of dozens of ligands, including many of the known carriers of $A \beta$ (Christensen and Birn, 2002). As a promiscuous receptor, megalin is also able to transcytose insulin (Orlando et al., 1998) and possibly IGF-I, at least in kidney epithelium (Obermuller et al., 2001). Therefore, serum IGF-I may cross the choroid plexus barrier through megalin. At the same 
time, megalin may enhance transport of $\mathrm{A} \beta$ in response to IGF. These possibilities make megalin a plausible effector at the choroid plexus of the actions of serum IGF-I in the brain.

\section{Materials and Methods}

Viral vectors. Lentiviral vectors using a four-plasmid transfection system were produced as described previously (Dull et al., 1998). cDNA constructs were inserted downstream of the mouse phosphoglycerate kinase 1 (PGK) promoter in a self-inactivating human immunodeficiency virus-1 (HIV-1) vector containing the woodchuck hepatitis virus posttranscriptional element (Zufferey et al., 1997). The packaging construct and the vesicular stomatitis virus G-protein envelope included the pCMV $\Delta$ R-8.92, pRSV-Rev, and pMD.G plasmids, respectively (Dull, 1988). The cDNA coding for green fluorescent protein (GFP) was subcloned in the BamHI/SalI site of the HIV-1-PGK transfer vector. A dominant-negative (KR) human IGF-I receptor (IGF-IR) kinase-dead mutant was inserted in the same site of the transfer vector. A cDNA coding for a portion corresponding to the two C-terminal extracellular cysteine-rich domains, the transmembrane part, and the entire cytoplasmic region of the megalin gene (miniMegalin) was subcloned in the BamHI-SalI site of the HIV-1-PGK transfer vector. A megalin small interfering RNA (siRNA) was ligated into the HIV-1 transfer vector between the XhoI and SalI sites. In this case, the HIV-1 vector included instead a human $\mathrm{H} 1$ promoter and a random DNA stuffer sequence. Candidate megalin siRNA sequences were designed with an OligoEngine (Seattle, WA) automated design tool. The sequence used in the present study comprised the 201-220 bp nucleotides of the megalin gene (GenBank accession number, L34049) in both sense and antisense orientation, separated by a nine nucleotide spacer sequence.

The transfer vector $(13 \mu \mathrm{g})$, the envelope $(3.75 \mu \mathrm{g})$, and the packaging plasmids $(3.5 \mu \mathrm{g})$ were cotransfected with calcium phosphate in human embryonic kidney $293 \mathrm{~T}$ cells $\left(5 \times 10^{6}\right.$ cells per dish) cultured in DMEM (Invitrogen, San Diego, CA) with 10\% FCS, 1\% glutamine, and 1\% penicillin/streptomycin. Medium was changed $2 \mathrm{~h}$ before transfection and replaced after $24 \mathrm{~h}$. Conditioned medium was collected $24 \mathrm{~h}$ later, cleared (1000 rpm for $5 \mathrm{~min}$ ), and concentrated $\sim 100$-fold $(19,000 \mathrm{rpm}$ for $1.5 \mathrm{~h}$ ). The pellet was resuspended in PBS with $1 \%$ bovine serum albumin, and the virus was stored at $-80^{\circ} \mathrm{C}$. Viral title was determined by HIV-1 p24 ELISA (PerkinElmer, Wellesley, MA). Empty vector (no insert) was used as control (void vector) in all experiments.

Experimental design. Adult ( 3 months of age) and aged ( $>30$ months of age) Wistar rats and adult C57BL/6 mice were used from our inbred colony. Liver-IGF-I-deficient (LID) mice (6-21 months of age) were from our inbred colony. Double-transgenic amyloid precursor protein/ presenilin-1 (APP/PS1) mice (1 year of age), a cross of Tg2576 (overexpressing human APP695) and mutant PS1 (M146L) mice, were used as a model of AD amyloidosis. Animals were used following European Economic Community guidelines. To minimize animal use, we initially compared responses of intact (sham) animals with those obtained in void-vector-treated animals (see below), and because no differences were appreciated, we used only void-vector animals as controls.

Vector suspensions ( $140 \mu \mathrm{g}$ HIV-1 p24 protein/ml; $6 \mu$ l per rat and 2 $\mu l$ per mouse) were stereotaxically injected in each lateral ventricle [brain coordinates ( $\mathrm{mm}$ from bregma): rat, 1 posterior, 1.2 lateral, 4 ventral; mouse, 0.6 posterior, 1.1 lateral, 2 ventral] with a $10 \mu \mathrm{l}$ syringe at 1 $\mu \mathrm{l} / \mathrm{min}$. In experiments to block the action of HIV-KR, similar amounts of HIV-wild-type IGF-IR were injected. Recombinant IGF-I (GroPep, Adelaide, Australia) was labeled with digoxigenin (Dig; Pierce, Rockford, IL) as described previously (Carro et al., 2000) and administered as a bolus injection either into the brain parenchyma [ $1 \mu \mathrm{g}$ per rat; stereotaxic coordinates ( $\mathrm{mm}$ from bregma): 3.8 posterior, 2 lateral, and 3.2 ventral] or through the carotid artery (10 $\mu \mathrm{g}$ per rat). CSF was collected under anesthesia from the cisterna magna. Animals were perfused transcardially with saline buffer or $4 \%$ paraformaldehyde in $0.1 \mathrm{~m}$ phosphate buffer, $\mathrm{pH}$ 7.4, for biochemical and immunohistochemical analysis, respectively.

A double-chamber choroid plexus epithelial cell-culture system mimicking the blood-CSF interface was used for in vitro studies, as described previously (Carro et al., 2002). Fresh DMEM containing vector particles
A
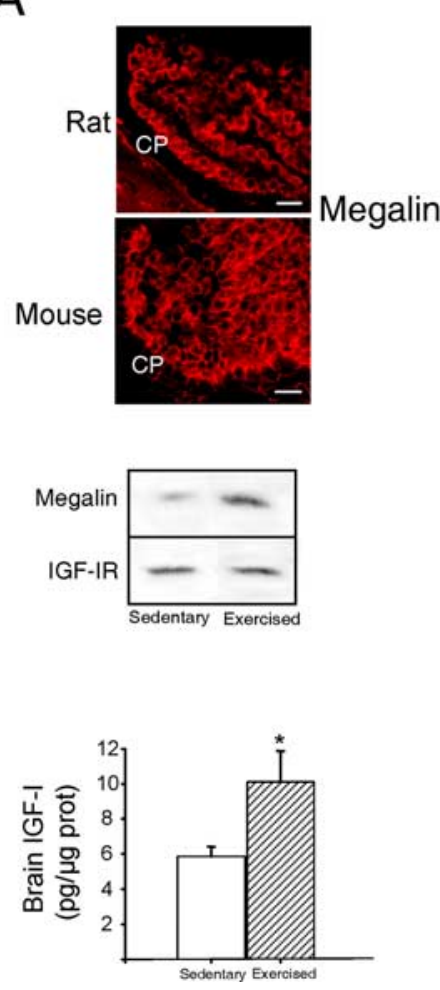

B

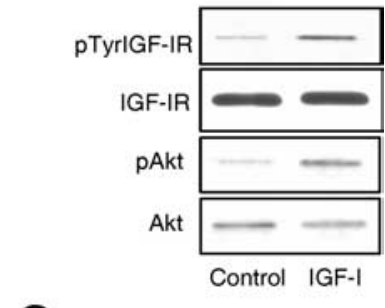

C

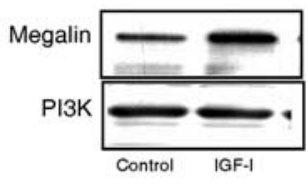

Figure 1. Modulation of choroid plexus megalin. $A$, Photomicrograph, Megalin immunoreactivity (red) is highly abundant in rat and mouse choroid plexus (CP). Histograms, IGF-Ilevels in cerebellum of $\mathrm{C} 57 \mathrm{BL} / 6$ mice were increased after exercise $\left(n=3-4 ;{ }^{*} p<0.05\right.$ vs sedentary mice by Student's $t$ test). Error bars represent SEM. Blot, Exercised mice show significantly increased megalin levels in choroid plexus, whereas levels of IGF-IRs in choroid plexus remained unchanged. A representative blot is shown. Quantitative densitometry showed a more than twofold increase in megalin levels ( $n=5 ; p<0.05$ vs sedentary mice by Student's test). Scale bars, $20 \mu \mathrm{m}$. B Injection of IGF-I (10 $\mu \mathrm{g})$ into the carotid of adult Wistar rats stimulates auto-phosphorylation of IGF-IRs in choroid plexus as well as phosphorylation of Akt, a canonical downstream signal of IGF-I. Levels of IGF-IRs and Akt remain unchanged $(n=4)$. p, Phosphorylated. C, Exposure of rat choroid plexus epithelial cells to IGF-I ( $100 \mathrm{~nm})$ resulted in significantly increased levels of megalin $24 \mathrm{~h}$ later. A representative blot is shown. Levels of megalin were normalized to PI3K levels in choroid plexus. Quantitative densitometry showed a twofold increase $(n=5 ; p<0.05$ vs control).

$(\sim 1 \mu \mathrm{g} / \mathrm{ml})$ and $8 \mu \mathrm{g} / \mathrm{ml}$ polybrene (Sigma, St. Louis, $\mathrm{MO}$ ) was added to the cultures and replaced after $24 \mathrm{~h}$. Cells were incubated another $24 \mathrm{~h}$, and thereafter IGF-I or Dig-labeled IGF-I (100 nm) was added to the lower chamber, and/or Dig-albumin $(1 \mu \mathrm{g} / \mathrm{ml})$, transthyretin (TTR; 1 $\mu \mathrm{g} / \mathrm{ml})$, or $\mathrm{A} \beta_{1-40} / \mathrm{A} \beta_{1-42}(10 \mu \mathrm{g} / \mathrm{ml})$ were added to the upper chamber. Twenty-four hours later, lower chamber medium was collected, and content of $\mathrm{A} \beta$ or $\mathrm{A} \beta$ carriers was determined by immunoblotting (see below). In other experiments, kinase inhibitors bisindolylamide (100 nM), Ro320432 (10 nM), wortmannin (100 nM), or 2'-amino-3'methoxyflavone (PD98059) $(25 \mu \mathrm{M})$ were added $1 \mathrm{~h}$ in advance in the upper chamber. Lower-chamber medium was collected and cells lysed and processed. IGF-I and albumin were labeled with digoxigenin-3-Omethylcarbonyl-aminocaproic-acid- $N$-hydroxy-succinimide ester (Boehringer Mannheim, Mannheim, Germany), as indicated by the manufacturer. Dig labeling of either IGF-I or albumin was done to distinguish the highly abundant endogenous IGF-I or albumin from those exogenously added. Treatments were done in duplicate-triplicate wells per experiment.

Results are shown as means \pm SEM. One-way ANOVA followed by post hoc Student's $t$ test was used to compare between groups.

Behavioral evaluation. Spatial memory was evaluated with an standard water maze test (Morris, 1984), as described in detail previously (Carro et al., 2001). Briefly, after a $1 \mathrm{~d}$ habituation trial (day 1 ) in which preferences between tank quadrants were ruled out, for the subsequent $2-5 \mathrm{~d}$ (rats) or $6 \mathrm{~d}$ 
A
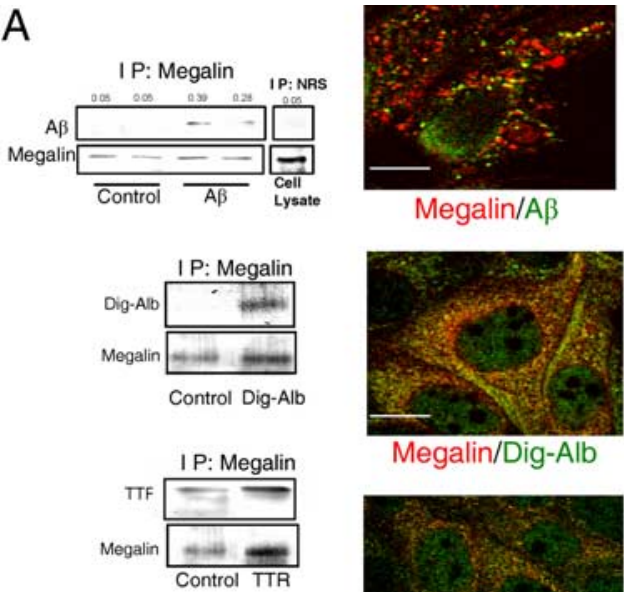

B

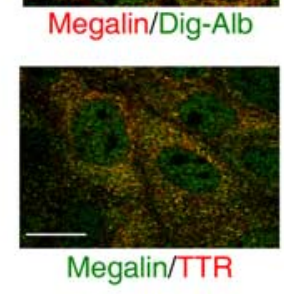

E

$A \beta$
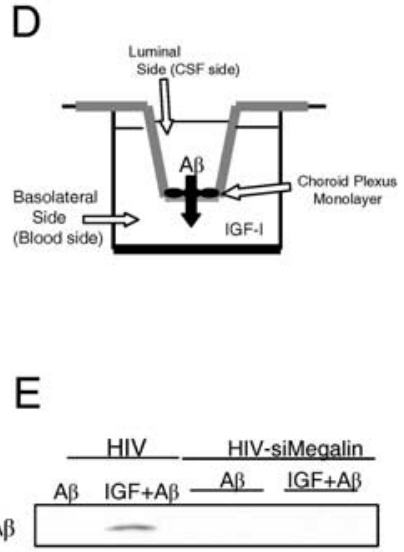

$\mathrm{F}$
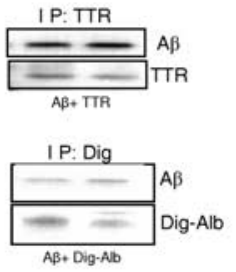

G

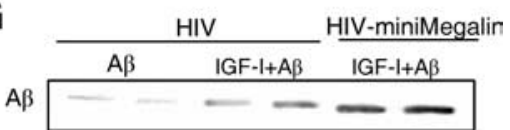

C

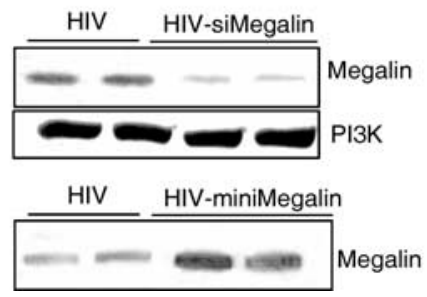

rule out possible sensorimotor and motivational differences between experimental groups. No alterations were found in any of the experimental groups. All animals were tested in four trials per day. Individual means for escape latency of the four trials were obtained previously to obtain group mean escape latency. Both path length and swim speed were measured for each animal in every trial with EthoVision software (Noldus Information Technology, Wageningen, The Netherlands). No significant differences were found between groups in any of the experimental groups, neither during acquisition nor retention. Behavioral data were analyzed by ANOVA and Student's $t$ test.

Animals were submitted to daily exercise on the treadmill as described in detail previously (Carro et al., 2000). C57BL/6 mice ran in the afternoon for $1 \mathrm{~h} / \mathrm{d}$ at $17 \mathrm{~m} / \mathrm{min}$ for 4 weeks (5 $\mathrm{d} /$ week). Control sedentary animals remained in the treadmill without running. Animals were killed $24 \mathrm{~h}$ after the last run, and tissue was processed immediately.

Immunoassays. Western blot (WB) and immunoprecipitation were performed as described previously (Carro et al., 2002). WB membranes were reblotted with either the same antibody used for immunoprecipitation or with unrelated proteins [phosphatidylinositol 3-kinase (PI3K), IGF-IR] as internal standards and to normalize for protein load. Levels of the protein under study were expressed relative to protein load in each lane. Densitometric analysis was performed using Quantity One software (Bio-Rad, Hercules, CA). To analyze A $\beta$ deposits, coronal brain sections were cut serially and preincubated in $88 \%$ formic acid and immunostained, as reported previously (Carro et al., 2002). For ELISA of total $A \beta$, we used the $4 \mathrm{G} 8$ antibody (Sigma) in the lower layer and anti$\mathrm{A} \beta_{1-40}$ or anti-A $\beta_{1-42}$ (Calbiochem, La Jolla, $\mathrm{CA}$ ) in the top layer. Both soluble and insoluble forms of $A \beta$ were extracted with formic acid and assayed as described previously (Suzuki et al., 1994). Brain IGF-I levels were measured by radioimmunoassay as described previously (Carro et al., 2000). As reported by Deane et al. (2004), megalin binds with greater affinity to $\mathrm{A} \beta_{1-40}$ than to $\mathrm{A} \beta_{1-42}$ (data not shown); therefore, we only analyzed megalin interactions with $\mathrm{A} \beta_{1-40}$. Mouse anti-A $\beta$ (Medical Biological Laboratory, Nagoya, Japan), which recognizes rodent and human $\mathrm{N}$-terminal $\mathrm{A} \beta$ forms, anti-albumin (Bethyl Laboratories, Montgomery, TX), anti-calbindin (Swant, Bellinzona, Switzerland), anti-digoxigenin (Boehringer Mannheim), anti-phospho-tau (AT8; Innogenetics, Gent, Belgium), anti-megalin, antitransthyretin, anti-caveolin-1, anti-early endosome antigen-1, anti-lysosome-associated membrane protein-2, anti-clathrin, and antiDab2 (all from Santa Cruz Biotechnology, Santa Cruz, CA) were used at 1:500-1:1000 di(mice), the animals learned to find a hidden platform (acquisition), followed by $1 \mathrm{~d}$ of probe trial without the platform, in which swimming speed was found to be similar in all groups, and the preference for the platform quadrant was evaluated. Nine to $10 \mathrm{~d}$ later, animals were tested for long-term retention (memory) with the platform placed in the original location. Retention was assessed for 2 consecutive days to avoid false extinction effects (Morris, 1984). On the last day, a cued version protocol was conducted to lution. Secondary antibodies were Alexa-coupled (Invitrogen) or biotinylated (Jackson ImmunoResearch, West Grove, PA).

\section{Results}

Because IGF-I is involved in the actions of exercise in the brain (for review, see Trejo et al., 2002), we determined in C57BL/6 
mice whether prolonged exercise affects megalin/LRP2 in choroid plexus (Fig. 1A) and found that, together with the expected increase in brain IGF-I (Fig. $1 \mathrm{~A}$, histograms), megalin levels in choroid plexus were augmented over twofold after 1 month of moderate running (Fig. 1A) $(p<0.05$ vs sedentary animals; $n=5)$. Because exercise stimulates brain uptake of serum IGF-I at least in part through the choroid plexus (Carro et al., 2000), we determined whether serum IGF-I targets choroid plexus cells. We found that IGFIRs in rat choroid plexus epithelium, which are highly abundant (Lee et al., 1993), become activated in response to systemic IGF-I (Fig. 1B). Furthermore, when rat choroid plexus epithelial cells are exposed to IGF-I, megalin levels increased twofold (Fig. $1 C)(n=5 ; p<0.05$ vs controls). Together, these observations suggest a link between choroid plexus megalin/LRP2 and serum IGF-I.

IGF-I regulates brain $\mathrm{A} \boldsymbol{\beta}$ clearance: role of choroid plexus megalin/LRP2

Most $\mathrm{A} \beta$ carriers share megalin/LRP2 as a common cargo receptor that binds $A \beta /$ carrier complexes (Zlokovic et al., 1996; Sousa et al., 2000; Barth and Argraves, 2001). Indeed, megalin from rat choroid plexus cells binds to $A \beta_{1-40}$ (Fig. $2 A$ ) and to $A \beta$ carrier proteins such as albumin or TTR (Fig. 2A). To facilitate its transport by megalin/LRP2, $\mathrm{A} \beta$ binds to its different carriers (Fig. $2 B$ ), as reported previously (Zlokovic et al., 1996; Deane et al., 2004). Because megalin has a greater affinity for $\mathrm{A} \beta_{1-40}$ than for $\mathrm{A} \beta_{1-42}$ (Deane et al., 2004 and data not shown), in these studies we used the former, more soluble form of $A \beta$.

We found that megalin is involved in IGF-I-induced transport of $A \beta_{1-40}$ across rat choroid plexus epithelial cells. RNA interference of megalin (siMegalin), which results in low megalin levels in rat choroid plexus cells (Fig. 2C), blocks IGF-Iinduced transport of $\mathrm{A} \beta$ across an epithelial monolayer, mimicking the CSF-blood interface at the choroid plexus (Fig. 2D,E and supplemental Fig. $1 A$, available at www.jneurosci.org as supplemental material). IGF-I-induced transcytosis of an $\mathrm{A} \beta$ carrier such as albumin was also impaired in the presence of siMegalin (Fig. $2 F$ and supplemental Fig. $1 B$, available at www. jneurosci.org as supplemental material). [Analysis of the effects of siMegalin on transport of another $\mathrm{A} \beta$ carrier such as TTR (supplemental Fig. $1 E$, available at www.jneurosci.org as supplemental material) was confounded by the fact that TTR is endogenously produced by choroid plexus cells (Schreiber, 2002), and its production is increased by IGF-I (supplemental Fig. $1 F$, available at www.
A

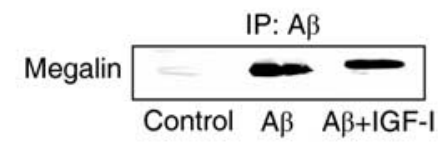

C
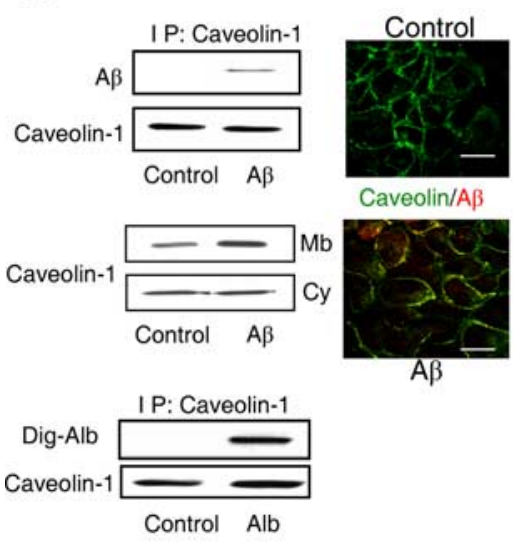

$\mathrm{E}$

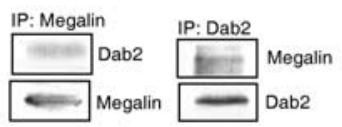

G

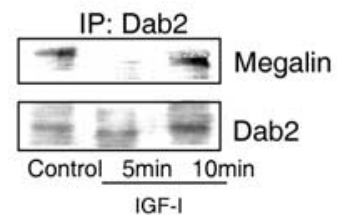

B
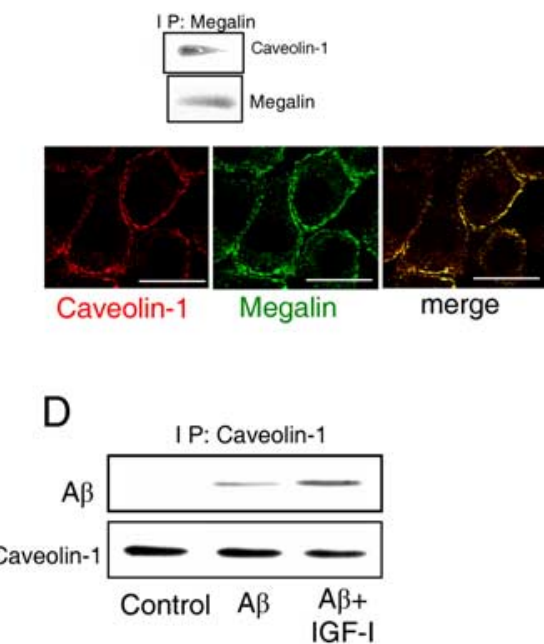

$\mathrm{F}$

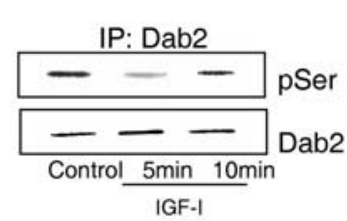

$\mathrm{H}$

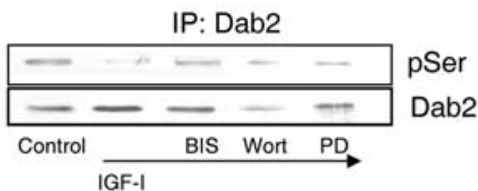

I

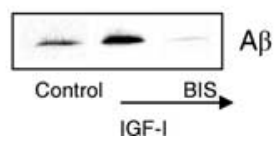

Figure 3. Mechanism of IGF-I-induced transport of $A \beta_{1-40}$ through choroid plexus cells. $A$, IGF-I does not modulate the association of $A \beta$ with megalin. The amount of $A \beta$ complexed with megalin did not change after exposure of rat choroid plexus cultures to IGF-I. Cells were immunoprecipitated with anti-A $\beta$ and blotted with anti-megalin. $\boldsymbol{B}$, Megalin in rat choroid plexus cells is constitutively associated with caveolin-1. Megalin coimmunoprecipitated and colocalized by immunocytochemical confocal analysis with caveolin-1. Scale bars, $10 \mu \mathrm{m}$. C, Megalin-mediated transport of $A \beta$ across rat choroid plexus cells involves association of the $A \beta$ /carrier complex with caveolin. Top blots, Caveolin-1 coimmunoprecipitates with exogenous $A \beta$ in choroid plexus cultures. No association is seen in untreated cultures (Control). Middle blots, The amount of caveolin-1 present in the membrane $(\mathrm{Mb})$ of choroid plexus cells is increased after addition of $A \beta$, whereas the cytoplasmic fraction (Cy) is not modified. Bottom blots, In cultured choroid plexus cells, caveolin-1 associates with albumin, an A $\beta$ carrier (Carro et al., 2002), as determined by coimmunoprecipitation. Dig-Alb, Digoxigenin-labeled albumin. Right micrographs, Peri-membrane localization of caveolin-1 staining is apparent in control rat cultures. After adding $A \beta$, caveolin- 1 colocalizes with it. Scale bars, $10 \mu \mathrm{m}$. D, IGF-I increases the amount of $A \beta$ associated with caveolin-1. $\boldsymbol{E}$, Megalin coimmunoprecipitates with Dab2 in choroid plexus epithelial cell cultures. Reciprocal coimmunoprecipation confirmed association of Dab2 with megalin. $\boldsymbol{F}$, IGF-linduces transient Ser-dephosphorylation of Dab2 in rat choroid plexus cells. Total Dab2 levels remained unchanged. p, Phosphorylated. G, IGF-I induces transient decoupling of Dab2 and megalin. Note that the time course coincides with dephosphorylation of Dab2 by IGF-I. Total Dab2 levels remain constant. $\boldsymbol{H}$, IGF-Iinduced dephosphorylation of Dab2 is blocked by bisindolylamine (BIS), a PKC inhibitor, whereas wortmannin (Wort; which inhibits PI3K) or PD98059 (PD; which blocks MAPK activation) did not affect IGF-I action. I, Blockade of PKC activity with bisindolylamine (BIS) abrogates IGF-I-induced translocation of $A \beta$ across the epithelial monolayer. Representative blots are shown throughout. $A$ minimum of four experiments were performed for each condition shown in this figure. IP, Immunoprecipitation.

jneurosci.org as supplemental material).] On the contrary, when rat choroid plexus cells overexpress miniMegalin (Fig. 2C), a fully functional shorter version of megalin (Larsson et al., 2003), IGFI-induced translocation of $\mathrm{A} \beta$ (or albumin) across the epithelial monolayer was enhanced (Fig. $2 G, H$ and supplemental Fig. $1 C, D$, 
available at www.jneurosci.org as supplemental material). IGF-I may enhance translocation of $\mathrm{A} \beta$ across the choroid plexus epithelium by increasing the association of $\mathrm{A} \beta$ to megalin, by increasing the internalization of the $A \beta /$ megalin complex, or both. The association of $A \beta$ with megalin was not modulated by IGF-I (Fig. $3 A$ ). However, endocytic transport of $\mathrm{A} \beta$ by megalin was increased after exposure to IGF-I. Megalin is associated to caveolin-1 (Fig. 3B), a protein present in caveolas that interacts with megalin (Sargiacomo et al., 1993). Accordingly, megalin-mediated transport of $\mathrm{A} \beta$ across choroid plexus cells involves association of the $A \beta /$ carrier complex with caveolin (Fig. $3 C$ ) but not with clathrin or early endosomes (data not shown). Thus, caveolin-1 in rat choroid plexus cells exposed to $A \beta$ associates with it, whereas the amount of caveolin in the cell membrane is increased (Fig. 3C). After addition of albumin, caveolin-1 also becomes associated with it (Fig. 3C). Furthermore, association of $A \beta$ with caveolin was enhanced by IGF-I (Fig. 3D).

Transport of cargo through megalin requires its internalization. This process is regulated by phosphorylation-dephosphorylation of docking proteins such as Dab2 (Oleinikov et al., 2000), which asssociates with megalin (Fig. 3E). IGF-I induced both dephosphorylation of Dab2 (Fig. $3 F$ ) and uncoupling of megalin to Dab2 (Fig. 3G) with a similar time course. Significantly, Dab2 uncoupling is required for megalin internalization (Morris et al., 2002). IGF-I required PKC activity to dephosphorylate Dab2, because bisindolylamine, a PKC inhibitor, abrogated this effect (Fig. 3H). Ro320432, another PKC inhibitor, confirmed the involvement of PKC in the action of IGF-I on Dab (data not shown). Other kinase inhibitors targeting canonical signaling by IGF-I such as PI3K or MAPK (mitogen-activated protein kinase) were ineffective (Fig. $3 H$ ). In agreement with a role of PKC in IGF-I induced internalization of megalin, inhibition of PKC resulted in abrogation of IGF-I-induced transport of $\mathrm{A} \beta$ across a rat choroid plexus monolayer (Fig. 3I).

The above data indicate that IGF-Iinduced transport of $\mathrm{A} \beta$ through the choroid plexus involves megalin internalization complexed to $A \beta$. Hence, we explored the biological significance of this process. In vivo interference of choroid plexus megalin through injection into the lateral ventricles (Fig. 4A) of a lentiviral vector coding for megalin siRNA (HIVsiMegalin), which decreased choroid plexus content of megalin (Fig. $4 A$ ), led to a significant increase in $\mathrm{A} \beta_{1-x}$ levels in adult rat cortex 6 months later (Fig. $4 B$ ) together with the appearance of scarce and small Congo red ${ }^{+}$deposits, a marker of $\mathrm{A} \beta$ deposits (Fig. $4 B$ ). High $\mathrm{A} \beta_{1-x}$

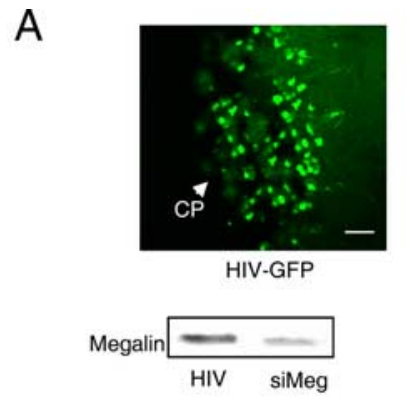

B
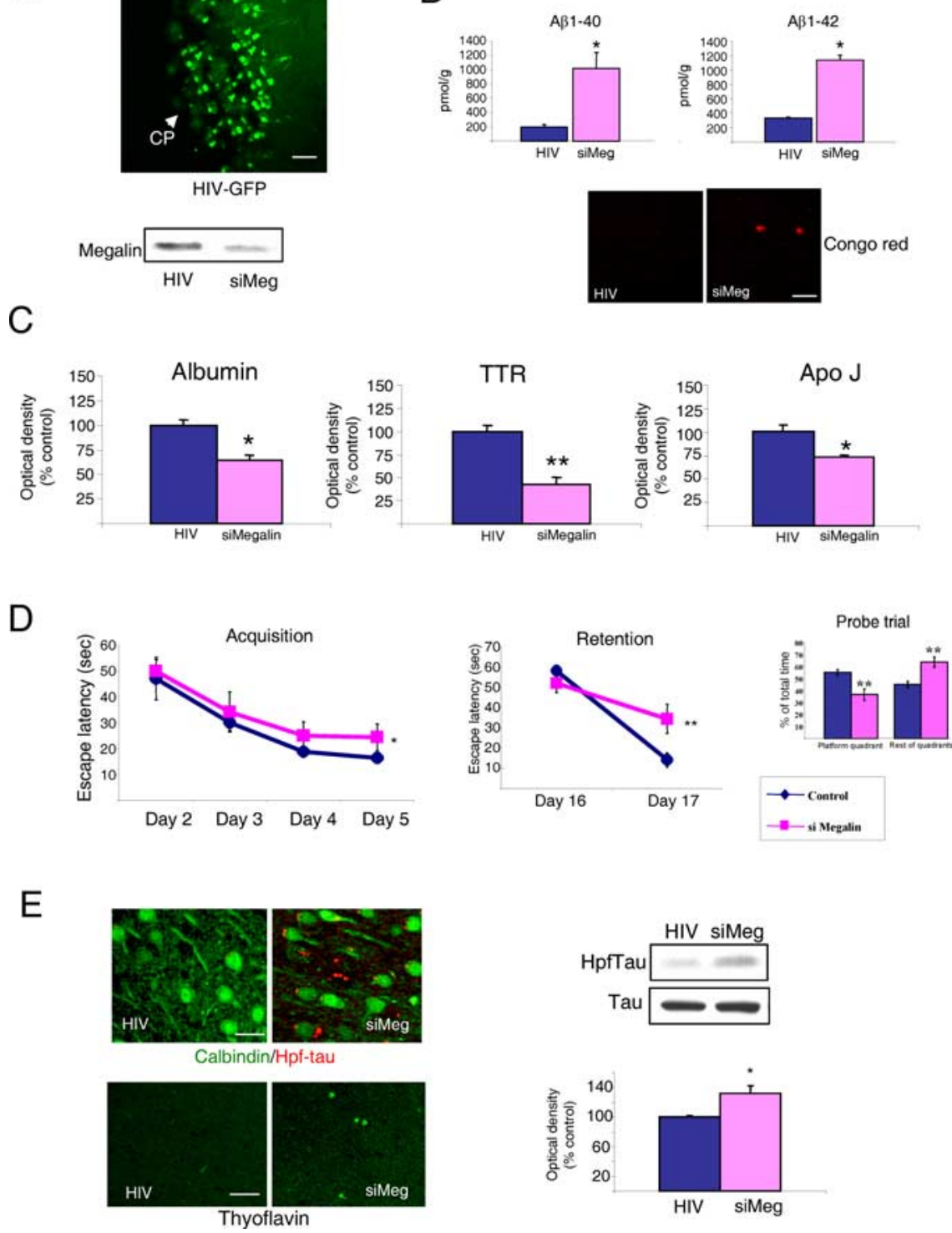

Figure 4. Blockade of megalin in choroid plexus of adult rats. $\boldsymbol{A}$, Photomicrograph, GFP expression in rat choroid plexus cells 3 months after a single intracerebroventricular injection of HIV-GFP $(n=6)$. Blot, Intraventricular HIV-siMegalin (siMeg) administration resulted in marked decrease in choroid plexus megalin levels 6 months later compared with HIV-injected controls. CP, Choroid plexus. Scale bar, 30 $\mu \mathrm{m} . \boldsymbol{B}$, Levels of $A \beta_{1-40}$ and $A \beta_{1-42}$ in rat brain cortex are markedly increased 6 months after blockade of choroid plexus megalin by intracerebroventricular injection of HIV-siMeg. Scarce and small Congo red ${ }^{+}$deposits were found only in brain cortex of siMeg rats. Scale bar, $20 \mu \mathrm{m}$. C, Brain cortex levels of $A \beta$ carriers albumin, $\Pi T R$, and apolipoprotein $\mathrm{j}$ (Apo J) were significantly decreased in siMeg rats 6 months after injection of the viral vector. $\boldsymbol{D}$, Performance in the water maze was also impaired by siMeg administration. Both learning (acquisition phase) and memory (retention) in the water maze were significantly deteriorated 6 months later in siMeg-injected rats $(n=$ 6). Probe trials indicate that whereas control (HIV) rats spent significantly longer time in the platform quadrant than in the rest of quadrants, siMeg animals were swimming in each quadrant the same time (no significant preference for the platform quadrant). Consequently, we also found significant differences between control and siMeg animals in platform quadrant preferences ( $n=4-6$ per group). ${ }^{*} p<0.05 ;{ }^{* *} p<0.01$ versus HIV-injected controls, by ANOVA followed by post hoc Student's $t$ test. $\boldsymbol{E}$, Brain Hpf-tau levels significantly increased after blockade of choroid plexus megalin (representative blot and quantitation histograms), with Hpf-tau-positive deposits present only in HIV-siMeg treated animals (top photomicrographs). Thyoflavin staining of Hpf-tau deposits were present only in megalinblocked rats (bottom). Scale bars, $20 \mu \mathrm{m} .{ }^{*} p<0.05 ;{ }^{* *} p<0.01$ versus HIV-injected controls, by Student's $t$ test. $n=4-6$ in all experiments. Error bars represent SEM.

levels are probably related to reduced clearance caused by lower brain levels of $\mathrm{A} \beta$ carriers such as albumin (Biere et al., 1996), transthyretin (Schwarzman et al., 1994), or apolipoprotein J (Hammad et al., 1997) after siMegalin injection (Fig. 4C).

Because amyloidosis may be associated with impaired cognition (Cleary et al., 2005), we determined whether HIV- 
siMegalin-injected rats show learning and memory disturbances. Using the water maze test (Morris, 1984), we found slightly but significantly impaired performance in rats as early as 3 months after HIV-siMegalin injection (data not shown), which was maintained for at least 6 months, compared with HIV-injected controls (Fig. 4D). Thus, siMegalin rats show decreased ability to learn the location of the hidden platform (acquisition phase of the Morris test) and memorize it (as evidenced in the retention test and probe trials). No differences in swim speed $(13.6 \pm 1.8 \mathrm{~cm} / \mathrm{s}$ in controls vs $14.5 \pm 2.1$ in siMegalin rats) or total path lengths $(855 \pm 58 \mathrm{~cm}$ in controls vs $869 \pm 81 \mathrm{~cm}$ in siMegalin; probe trial paths) were observed to account for these deficits.

Because amyloidosis is associated to brain deposits of $\mathrm{Hpf}$ tau in AD brains, we determined whether Hpf-tau was present in siMegalin-treated rats. Using the AT-8 anti-Hpf-tau antibody, we found abundant immunoreactive deposits of small size and increased levels of Hpf-tau in rats treated for 6 months. The appearance of thyoflavin-positive aggregates, a histochemical marker of Hpf-tau (Fig. 4E), confirmed the presence of abnormal tau.

\section{Megalin mediates transport of IGF-I through the choroid plexus}

Blood-borne IGF-I enters into the brain at least in part through the choroid plexus (Carro et al., 2000), but the mechanisms involved are not clear (Carro et al., 2000; Pulford and Ishii, 2001). As shown above, low megalin levels after siMegalin in the rat choroid plexus are associated to the appearance of Hpf-tau in brain and cognitive loss. Because megalin may transport IGF-I (Obermuller et al., 2001), entrance of serum IGF-I into the brain through the choroid plexus could be compromised in the absence of normal megalin levels, because low IGF-I input is related to tau hyperphosphorylation (Schubert et al., 2003) and cognitive loss (Sytze and Aleman, 2004).

Indeed, megalin binds to IGF-I, as determined by coimmunoprecipitation analysis and immuno-colocalization in rat choroid plexus epithelial cells (Fig. 5A). Furthermore, siMegalin interferes with translocation of IGF-I through an epithelial rat choroid plexus cell monolayer (Fig. $5 B$ ), whereas in choroid plexus cells expressing miniMegalin, IGF-I translocation is enhanced (Fig. 5C). Therefore, megalin is required not only for transport of $A \beta$ out of the brain, as already suggested (Zlokovic et al., 1996), but also for translocation of IGF-I into the CSF across choroid plexus epithelial cells. We further examined this latter aspect in vivo. When megalin function is interfered in the rat choroid plexus by intraventricular injection of HIVsiMegalin, IGF-I blood-to-CSF transport is interrupted (Fig. 5D). Significantly, abolition of this blood-borne IGF-I flux partially impairs serum IGF-I signaling on brain tissue. Whereas in control rats (void-vector infected), intracarotid administration of IGF-I stimulates Akt phosphorylation in brain parenchyma (hippocampus), this stimulation is slightly but significantly reduced when choroid plexus transport of serum IGF-I is blocked by intracerebroventricular HIVsiMegalin (Fig. $5 E)$ ( $p<0.05$ vs HIV plus IGF-I-injected rats). Transport of IGF-I across the choroid plexus does not exclusively depend on megalin; proper IGF-IR function is also required. In rats in which the choroid plexus expresses a KR IGF-IR, transport of IGF-I into the CSF is also interrupted (Fig. $5 F$ ). Because IGF-I still stimulates Akt phosphorylation in choroid plexus, whereas megalin levels are interfered with siMegalin (Fig. 5G), this suggests that transport of IGF-I through the IGF-IR/megalin pathway is independent of IGF-IR signaling through Akt. In fact,
A
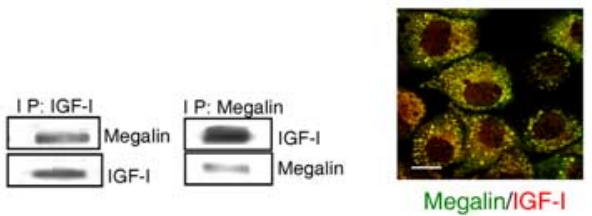

B

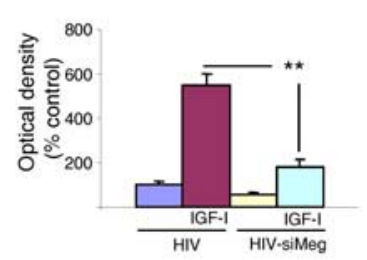

$\mathrm{C}$



D
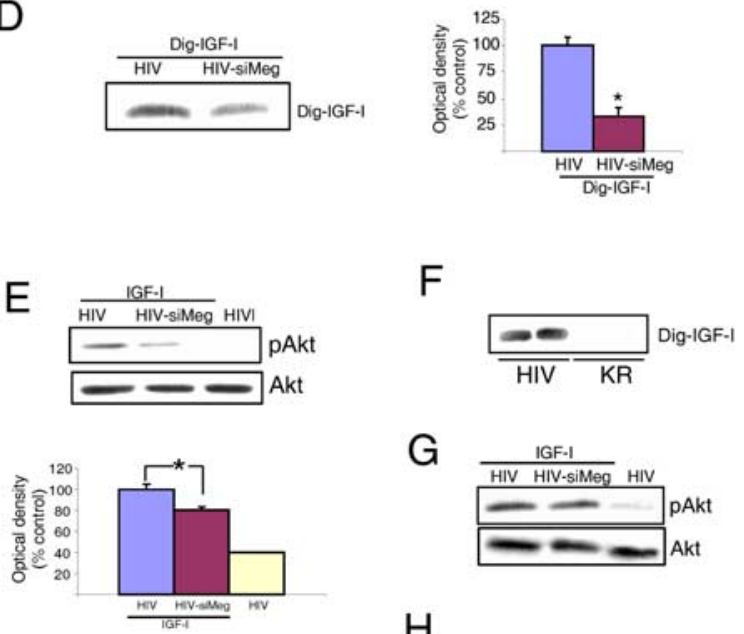

G

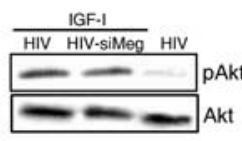

$\mathrm{H}$

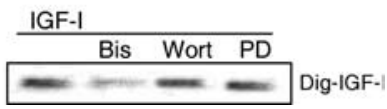

Figure 5. Transport of IGF-I across the choroid plexus. $A$, Megalin in rat choroid plexus cells interacts with IGF-I. Blots, Reciprocal coimmunoprecipitation of megalin with IGF-I after adding the latter to choroid plexus cultures. Photomicrographs, Megalin (green) and IGF-I (red) colocalize in cultured choroid plexus epithelial cells. Scale bar, $10 \mu \mathrm{m}$. $\boldsymbol{B}$, Rat choroid plexus cells expressing siMegalin translocate significantly less IGF-I from the lower to the upper culture chamber (see Fig. 1E). ${ }^{* *} p<0.01$ versus HIV-infected cells by Student's $t$ test. $\boldsymbol{C}$, When rat choroid plexus cells express miniMegalin, the amount of translocated IGF-I is significantly increased. ${ }^{* *} p<0.01$ by Student's $t$ test. $\boldsymbol{D}$, Rats infected with HIV-siMeg in the choroid plexus translocate significantly less Dig-IGF-I from the blood into the CSF. Representative blot and quantitative histograms are shown. ${ }^{*} p<0.05$ versus HIV-infected rats by Student's $t$ test $(n=$ 4). $\boldsymbol{E}$, In rats expressing siMeg in the choroid plexus, intracarotid injection of IGF-I (10 $\mu \mathrm{g}$ per rat) results in significantly lower stimulation of Akt in brain parenchyma (hippocampus) $1 \mathrm{~h}$ later. Representative blots and quantitation histograms are shown. Total Akt remained unchanged. $\boldsymbol{F}$, Rats expressing a KR IGF-IR in choroid plexus (HIV-KR rats) did not translocate Dig-IGF-I from the blood into the CSF. The blot shows Dig-IGF-I in CSF of HIV (control) and HIV-KR rats. Two rats per treatment are shown $(n=5)$. G, Megalin is not required for IGF-Iinduced activation of Akt in rat choroid plexus. After infection of choroid plexus with HIV-siMeg, intracarotid IGF-l is still able to stimulate phosphorylation of Akt in choroid plexus. $\boldsymbol{H}$, Inhibition of PKC with bisindolylamine (Bis), but not of PI3K/Akt with wortmannin (Wort) or MAPK with PD98059 (PD), abrogates passage of Dig-IGF-I across a rat choroid plexus epithelial monolayer. Representative blots are shown. At least three independent in vitro experiments were run for each condition. IP, Immunoprecipitation; siMeg, siMegalin; miniMeg, miniMegalin; p, phosphorylated.

inhibition of PKC with bisindolylamine, but not inhibition of PI3K/Akt with wortmannin or MAPK with PD98059, inhibits IGF-I transcytosis by megalin in a choroid plexus monolayer (Fig. 5H). 


\section{Choroid plexus megalin and blood- borne IGF-I neuroprotection}

Because brain amyloidosis (Cleary et al., 2005) and low serum IGF-I levels are associated with cognitive impairment (Sytze and Aleman, 2004), if megalin is involved in brain $A \beta$ clearance and at the same time in entrance of serum IGF-I into the CSF, experimental manipulation of its activity may help understand the role of $\mathrm{A} \beta$ clearance and serum IGF-I in cognitive disturbances.

First, we aimed to ameliorate cognitive loss in different rodent models of cognitive disturbance by enhancing $A \beta$ clearance and entrance of serum IGF-I through increased megalin levels. As described above, we delivered a lentiviral (HIV) vector coding for miniMegalin to the choroid plexus by intracerebroventricular injection. This resulted in increased choroid plexus levels of megalin 6 months later (Fig. 6A). In these different rodent models, we determined performance in the water maze, brain amyloid, and Hpf-tau levels (using the AT- 8 antibody). The results are summarized in Table 1, Figure 6, and supplemental Figure 2 (available at www. jneurosci.org as supplemental material). In APP/PS1 mice, a well established model of $\mathrm{AD}$-like cognitive loss associated with very high amyloid levels (Borchelt et al., 1997), increasing choroid plexus megalin resulted in a significant improvement in learning (acquisition) scores compared with void-vector-injected littermates (supplemental Fig. 2A, available at www. jneurosci.org as supplemental material). In parallel, Hpf-tau deposits were less apparent (Fig. $6 C$, compare $c, i$ ) and Hpf-tau levels significantly decreased (Table 1 ), whereas amyloid content did not change (Table 1). Next, we analyzed LID mice, a model of cognitive loss associated with premature brain amyloidosis and low serum IGF-I (Carro et al., 2002). Minimegalin injection in LID mice elicited a reduction in $\mathrm{A} \beta_{1-40}$ (but not $\mathrm{A} \beta_{1-42}$ ) (Table 1), disappearance of scarce Hpf-tau deposits (using the AT- 8 antibody) (Fig. $6 C d, C e)$, a significant reduction in Hpftau levels (Table 1), and restored watermaze learning and memory (supplemental Fig. $2 B$, available at www.jneurosci.org as supplemental material). We also analyzed whether animals with severe cognitive impairment (unable to learn the location of the platform in the water maze) (supplemental Fig. 2C, available at www. jneurosci.org as supplemental material), as found in very old rats (30 months of age), were amenable to the beneficial actions of megalin overexpression. However,
A

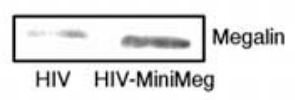

B
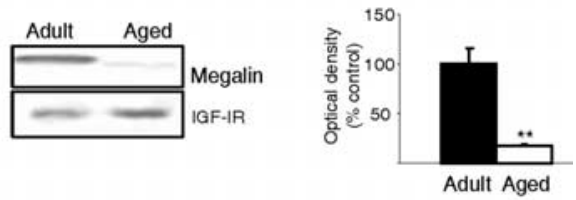

C


APP/PS1 mice
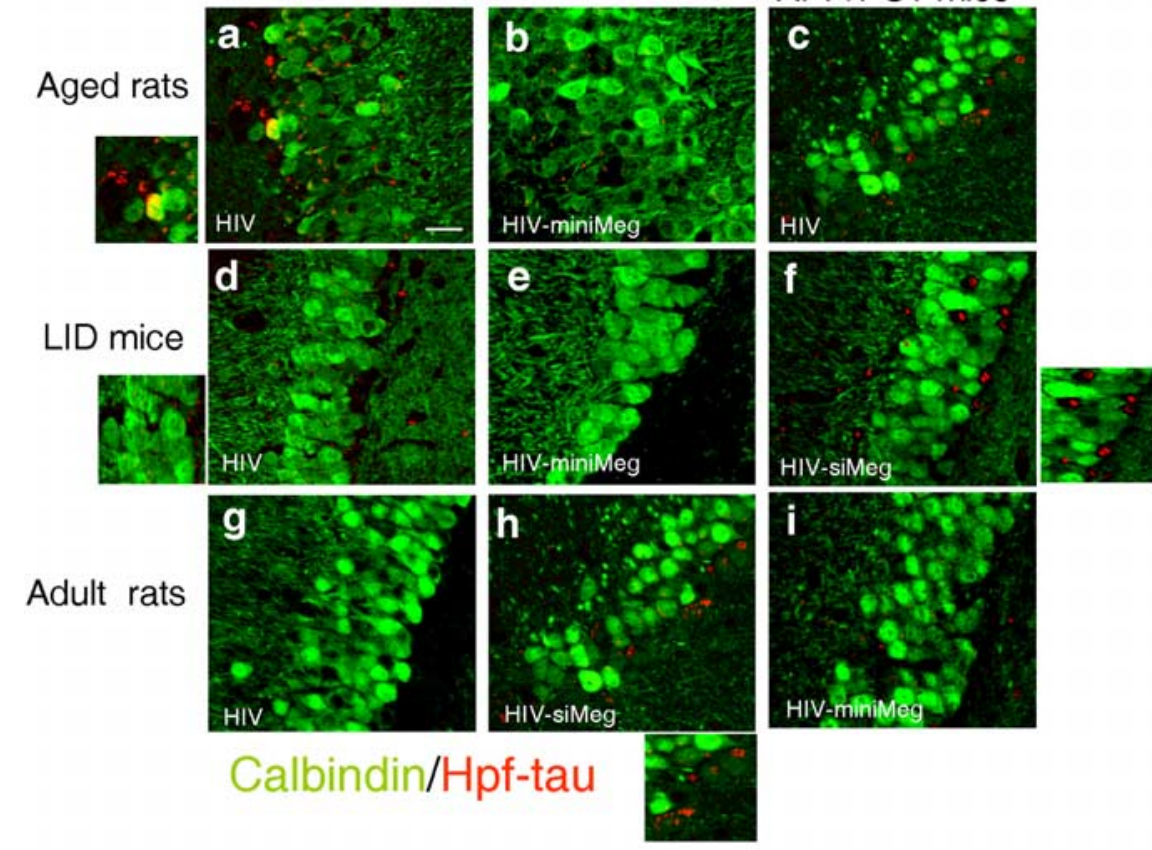

Calbindin/Hpf-tau

Hiv-minimeg

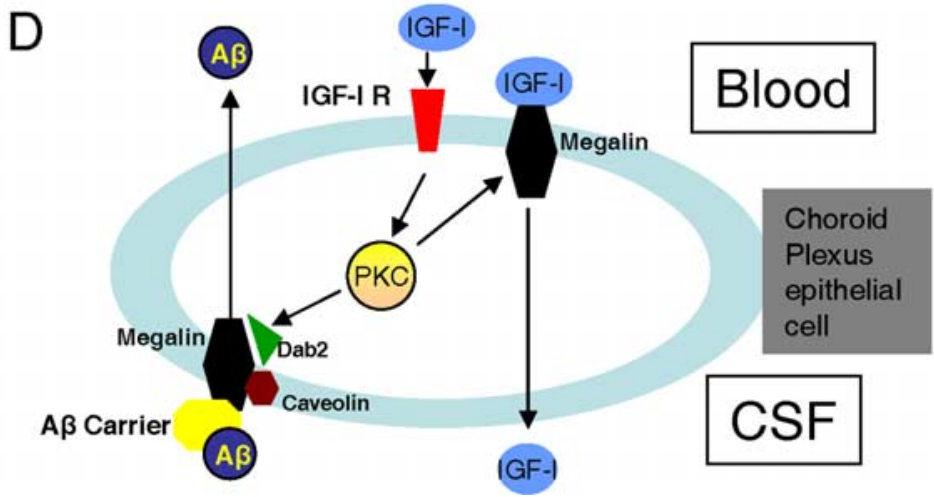

Figure 6. Role of megalin in choroid plexus. $A$, HIV-directed expression of miniMegalin (miniMeg) in choroid plexus of old rats results in increased megalin levels 6 months after injection, compared with HIV-injected controls. Representative blot is shown $(n=4) . \boldsymbol{B}$, Old rats have decreased megalin content in choroid plexus compared with adult animals. Representative blot and quantitation histograms. ${ }^{* *} p<0.01$ versus adult rats by Student's t test $(n=4)$. Error bars represent SEM. C, Hpf-tau deposits (red) within the pyramidal cell layer of the hippocampus in different rodent models of cognitive deterioration after modulation of megalin levels in choroid plexus. Neurons are stained with calbindin (green). $\mathbf{C a}, \boldsymbol{C b}, \mathrm{Hpf}$-tau staining, readily detectable in aged rats (30 months of age), is less prominent in aged rats expressing miniMeg in choroid plexus for 6 months. The left inset shows magnification of deposits in Ca. Cc, (f, Ci, Scattered Hpf-tau deposits in APP/PS1 mice become more apparent after reduction of megalin levels with siMeg (Cf), whereas they are not substantially modified after miniMeg expression (C) . The right inset shows magnification of deposits in $\mathbf{C f}$. Cd, Ce, LID mice have low levels of Hpf-tau deposits that disappear after miniMeg expression for 3 months. The right inset shows magnification of small deposits in $\mathbf{C d}$. Cg, $\mathbf{C h}$, Injection of HIV-siMeg to adult rats resulted in the appearance of scattered Hpf-tau deposits in the hippocampus. The inset in Ch shows magnification of the deposits. Representative hippocampal sections are shown. Changes in Hpf-tau levels were quantified by Western blot (see Results). Control animals received void HIV vector intracerebroventricular injections in all cases. Scale bar, $20 \mu \mathrm{m}$. min Meg, miniMegalin; siMeg, siMegalin. D, Functional interactions between serum IGF-I and choroid plexus megalin. Serum IGF-Istimulates its receptor at epithelial choroid plexus cells to induce its own transport across the cell via megalin. Serum IGF-I also enhances transport by megalin of $A \beta$ complexed with its carriers from the CSF to the blood through a caveolin-dependent endocytic pathway involving IGF-I-induced decoupling ofDab2 to megalin. IGF-I requires PKCactivity, both to favor transport of A $\beta$ /carrier complexes as well as to be transported itself by megalin. Whether megalin binds IGF-I bound to the IGF-I receptor or free IGF-I requires additional analysis. 
Table 1. Modification of choroid plexus megalin activity in rodent models of cognitive impairment and its effect on $A \beta$ levels, Hpf-tau, and cognition

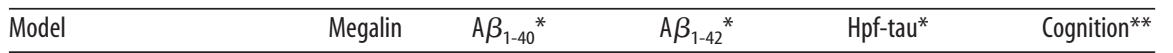

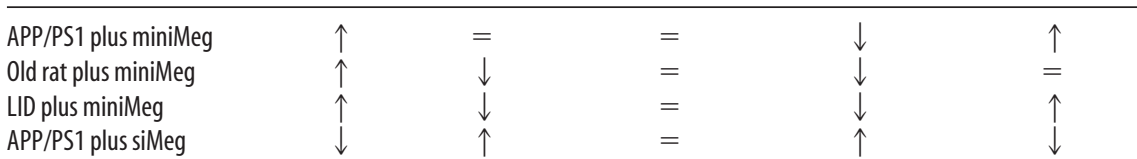

Before treatment, all animal models had significantly high $\mathrm{A} \beta$ and Hpf-tau levels and deteriorated cognition. Arrows indicate significant changes in each parameter tested after modulation of megalin levels. =, Impairment remains; miniMeg, miniMegalin; siMeg, siMegalin.

${ }^{*} p<0.05$ versus respective control (HIV)-injected animals, by Student's $t$ test; ${ }^{* *} p<0.05$, one-way ANOVA followed by Student's $t$ test; $n=6-8$ animals per experimental group.

no correlation was found between cognition and biochemical changes in response to increased megalin. Overexpression of miniMegalin in choroid plexus of very old rats did not improve learning, although brain $\mathrm{A} \beta_{1-40}$ levels were significantly decreased (but not $\mathrm{A} \beta_{1-42}$ ) (Table 1), Hpf-tau deposits were less obvious (Fig. 6Ca, Cb), and Hpf-tau levels were significantly lowered (Table 1).

Notably, intact old rats have very low levels of megalin in the choroid plexus, compared with adult animals (Fig. 6B). Finally, we examined whether reduced megalin could contribute to progress of cognitive loss. APP/PS1 mice infected with HIVsiMegalin showed significantly worsened memory (Table 1), increased Hpf-tau levels (Table 1), Hpf-tau deposits become more apparent (Fig. $6 C c, C f$ ), and $\mathrm{A} \beta_{1-40}$ content increased (Table 1 and supplemental Fig. $2 A$, available at www.jneurosci.org as supplemental material).

\section{Discussion}

The present findings indicate that megalin/LRP2 in choroid plexus epithelium is involved in regulation of $\mathrm{A} \beta$ clearance by serum IGF-I and in transport of this abundant serum growth factor from the bloodstream into the CSF. Because both exercise and IGF-I increase megalin in choroid plexus, it is possible that megalin participates in the role of serum IGF-I in exercise neuroprotection. For example, both exercise and IGF-I lower amyloidosis in mouse models of AD (Carro et al., 2002, 2005a; Adlard et al., 2005). Conceivably, exercise may ameliorate amyloid load by stimulating the IGF-I/megalin pathway in choroid plexus. Therefore, pharmacological stimulation of this pathway may mimic the beneficial actions of exercise and environmental enrichment on amyloid load (Adlard et al., 2005; Lazarov et al., 2005). This possibility warrants additional study.

Megalin/LRP2 is a cargo receptor involved in polarized transport of widely different proteins. Its biological role is best characterized in renal epithelium, participating in blood-urine homeostasis (Christensen and Birn, 2002). At the blood-CSF interface, its role is not well known, although previous work indicated the involvement of megalin, together with endothelial LRP1, in A $\beta$ clearance (Zlokovic et al., 1996; Deane et al., 2004; Tanzi and Bertram, 2005). The present findings support and extend these observations, suggesting a bifunctional activity of choroid plexus megalin. As summarized in Figure 6D, we suggest that in response to IGF-IR activation by serum IGF-I, megalin will transport $A \beta /$ carrier complexes from the CSF into the blood through a PKC-dependent pathway. This endocytic route involves IGF-I-induced increases in the interaction of megalin $\mathrm{A} \beta$ / carrier complexes with caveolin through IGF-I-induced decoupling of megalin to the cytoplasmic docking protein Dab2. In turn, blood-borne IGF-I will be transported into the CSF through megalin, also in a PKC-dependent manner. The latter is not surprising in view of the ability of megalin to transport different growth factors and hormones (Christensen and Birn, 2002). This poses megalin as an important effector of serum IGF-I neuroprotection and as a possible new target in Alzheimer's research. Indeed, enhancement of megalin/LRP2 activity in the choroid plexus may represent a novel way to increase cognitive performance. An additional theoretical possibility would be gene therapy via intravenous injection of megalin-Trojan horse vectors (Schlachetzki et al., 2004) in dementia disorders.

This dual action of megalin may be essential for neuro-surveillance by serum IGF-I (Torres-Aleman, 2000), including brain A $\beta$ clearance (Carro et al., 2002), inhibition of tau phosphorylation (Hong and Lee, 1997) or amyloid neurotoxicity (Niikura et al., 2001), and maintenance of cognitive function (Sytze and Aleman, 2004). Clearance of $\mathrm{A} \beta$ will diminish its accumulation in brain and consequently its neurotoxicity (Cleary et al., 2005), probably including the appearance of Hpf-tau staining (Hoshi et al., 2003). Entrance of serum IGF-I into the brain, which results in stimulation of IGF-I-dependent pathways such as Akt, will inhibit GSK-3, a tau kinase involved in AD (Hanger et al., 1992), and in this way will contribute to low levels of Hpf-tau. Many studies link Hpf-tau and dementia (Avila et al., 2004). Although mechanisms relating cognitive function to serum IGF-I levels are not established, many of the known neuroprotective actions of IGF-I are in all probability involved. These not only include inhibition of amyloid toxicity (Niikura et al., 2001) and Hpf-tau accumulation (Schubert et al., 2003), as already mentioned. Stimulation by IGF-I of brain perfusion (Lopez-Lopez et al., 2004), neurogenesis (Aberg et al., 2000; Trejo et al., 2001), neuronal excitability (Carro et al., 2000), synaptic plasticity (Nunez et al., 2003), neuronal resilience (Carro et al., 2001), glucose uptake (Bondy and Cheng, 2002), neurotrophins (Carro et al., 2000), and probably many other effects still to be characterized surely contribute to functional preservation.

The above conclusions are based on brain disturbances observed after manipulating megalin levels. Thus, lowering choroid plexus megalin in adult rats originates large increases in brain $\mathrm{A} \beta$ content and reduction of serum IGF-I entrance into the CSF. These observations are corroborated by reduced in vitro $\mathrm{A} \beta$ or IGF-I passage through a choroid plexus monolayer expressing megalin siRNA. Significant increases in AT- $8^{+} \mathrm{Hpf}$-tau in brain, together with loss in spatial learning and memory, are also seen after reducing megalin levels in vivo. On the other hand, in rodents in which cognition is already compromised, enhanced megalin expression in choroid plexus corrects moderate, but not severe, cognitive deficits. In all instances, Hpf-tau is reduced, whereas the (modest) reduction of amyloidosis observed in some, but not all, cases depends on its severity and only affects $\mathrm{A} \beta_{1-40}$. The latter agrees with the observation that megalin preferentially binds $A \beta_{1-40}$ (Deane et al., 2004). These findings suggest that lowering Hpf-tau, rather than reducing amyloidosis, correlates better with cognitive improvement and confirm that the choroid plexus participates in clearance of $A \beta_{1-40}$ (Zlokovic, 2004). However, when brain $A \beta$ levels are very high, such as in APP/PS1 mice, potentiation of this megalin route is insufficient, suggesting that overall $\mathrm{A} \beta$ clearance may be disrupted in conditions of severe amyloidosis. Nevertheless, costimulation of other $\mathrm{A} \beta$ clearance pathways, such as endothelial LRP1 (Deane et al., 2004), may prove an efficient way to eliminate excess $\mathrm{A} \beta$ under pathological circumstances. 
These findings indicate that the brain barrier at the choroid plexus epithelium (and most likely at the brain vessel endothelium as well) (Lopez-Lopez et al., 2004) constitutes a major target of circulating IGF-I. Activation of IGF-IR in the choroid plexus by blood-borne IGF-I will lead to its transport into the CSF (in the presence of dominant-negative IGF-I receptor this transport is blocked), enhanced outward transport of $A \beta /$ carrier complexes (together with inward transport of $A \beta$ carriers) (Carro et al., 2002), increased megalin levels, and augmented transthyretin production. As shown by pharmacological inhibition of PKC, IGF-I stimulates cargo activity of megalin through this kinase (Fig. 6D). Therefore, activation of PKC by IGF-I may be an important pathway in downstream activation of IGF-IRs at the choroid plexus. However, additional molecular dissection of this pathway is required. Because the choroid plexus, together with brain vessels, contains the highest levels of IGF-IRs in brain tissue (Lee et al., 1993), further insight into the pathways of IGF-IRs at the blood-brain barriers will advance our understanding of the neuroprotective role of IGF-I. This will help develop new therapeutic targets.

These data argue for a crucial role of choroid plexus megalin in neuroprotection by IGF-I, suggesting that megalin dysfunction may be involved in the pathogenesis of late-onset AD. The latter is reinforced by the fact that megalin is reduced with age, which in turn is the major risk factor in AD. These findings also suggest that targeting megalin expression may be an effective therapeutic strategy for treating AD. Because modulating the activity of the IGF-IR at the choroid plexus originates a similar pattern of biochemical and functional modifications in the brain (Carro et al., 2005b), we conclude that the IGF-IR/megalin pathway in the choroid plexus is of remarkable neuroprotective significance.

\section{References}

Aberg MA, Aberg ND, Hedbacker H, Oscarsson J, Eriksson PS (2000) Peripheral infusion of IGF-I selectively induces neurogenesis in the adult rat hippocampus. J Neurosci 20:2896-2903.

Adlard PA, Perreau VM, Pop V, Cotman CW (2005) Voluntary exercise decreases amyloid load in a transgenic model of Alzheimer's disease. J Neurosci 25:4217-4221.

Avila J, Lucas JJ, Perez M, Hernandez F (2004) Role of tau protein in both physiological and pathological conditions. Physiol Rev 84:361-384.

Barth JL, Argraves WS (2001) Cubilin and megalin: partners in lipoprotein and vitamin metabolism. Trends Cardiovasc Med 11:26-31.

Biere AL, Ostaszewski B, Stimson ER, Hyman BT, Maggio JE, Selkoe DJ (1996) Amyloid beta-peptide is transported on lipoproteins and albumin in human plasma. J Biol Chem 271:32916-32922.

Bondy CA, Cheng CM (2002) Insulin-like growth factor-1 promotes neuronal glucose utilization during brain development and repair processes. Int Rev Neurobiol 51:189-217.

Bondy CA, Lee WH (1993) Patterns of insulin-like growth factor and IGF receptor gene expression in the brain. Functional implications. Ann NY Acad Sci 692:33-43.

Borchelt DR, Ratovitski T, van Lare J, Lee MK, Gonzales V, Jenkins NA, Copeland NG, Price DL, Sisodia SS (1997) Accelerated amyloid deposition in the brains of transgenic mice coexpressing mutant presenilin 1 and amyloid precursor proteins. Neuron 19:939-945.

Carro E, Nunez A, Busiguina S, Torres-Aleman I (2000) Circulating insulinlike growth factor I mediates effects of exercise on the brain. J Neurosci 20:2926-2933.

Carro E, Trejo JL, Busiguina S, Torres-Aleman I (2001) Circulating insulinlike growth factor I mediates the protective effects of physical exercise against brain insults of different etiology and anatomy. J Neurosci 21:5678-5684.

Carro E, Trejo JL, Gomez-Isla T, LeRoith D, Torres-Aleman I (2002) Serum insulin-like growth factor I regulates brain amyloid-beta levels. Nat Med 8:1390-1397.
Carro E, Trejo JL, Gerber A, Loetscher H, Torrado J, Metzger F, TorresAleman I (2005a) Therapeutic actions of insulin-like growth factor I on APP/PS2 mice with severe brain amyloidosis. Neurobiol Aging, in press.

Carro E, Trejo JL, Spuch C, Bohl D, Heard JM, Torres-Aleman I (2005b) Blockade of the insulin-like growth factor I receptor in the choroid plexus originates Alzheimer's like neuropathology in rodents: new cues into the human disease. Neurobiol Aging, in press.

Christensen EI, Birn H (2002) Megalin and cubilin: multifunctional endocytic receptors. Nat Rev Mol Cell Biol 3:256-266.

Cleary JP, Walsh DM, Hofmeister JJ, Shankar GM, Kuskowski MA, Selkoe DJ, Ashe KH (2005) Natural oligomers of the amyloid-beta protein specifically disrupt cognitive function. Nat Neurosci 8:79-84.

Deane R, Wu Z, Sagare A, Davis J, Du YS, Hamm K, Xu F, Parisi M, LaRue B, Hu HW, Spijkers P, Guo H, Song X, Lenting PJ, Van Nostrand WE, Zlokovic BV (2004) LRP/amyloid beta-peptide interaction mediates differential brain efflux of Abeta isoforms. Neuron 43:333-344.

Dull HB (1988) Behind the AIDS mailer. Am J Prev Med 4:239-240.

Dull T, Zufferey R, Kelly M, Mandel RJ, Nguyen M, Trono D, Naldini L (1998) A third-generation lentivirus vector with a conditional packaging system. J Virol 72:8463-8471.

Hammad SM, Ranganathan S, Loukinova E, Twal WO, Argraves WS (1997) Interaction of apolipoprotein J-amyloid beta-peptide complex with low density lipoprotein receptor-related protein-2/megalin. A mechanism to prevent pathological accumulation of amyloid beta-peptide. J Biol Chem 272:18644-18649.

Hanger DP, Hughes K, Woodgett JR, Brion JP, Anderton BH (1992) Glycogen synthase kinase-3 induces Alzheimer's disease-like phosphorylation of tau: generation of paired helical filament epitopes and neuronal localisation of the kinase. Neurosci Lett 147:58-62.

Hong M, Lee VM (1997) Insulin and insulin-like growth factor-1 regulate tau phosphorylation in cultured human neurons. J Biol Chem 272:19547-19553.

Hoshi M, Sato M, Matsumoto S, Noguchi A, Yasutake K, Yoshida N, Sato K (2003) Spherical aggregates of beta-amyloid (amylospheroid) show high neurotoxicity and activate tau protein kinase I/glycogen synthase kinase3beta. Proc Natl Acad Sci USA 100:6370-6375.

Larsson M, Hjalm G, Sakwe AM, Engstrom A, Hoglund AS, Larsson E, Robinson RC, Sundberg C, Rask L (2003) Selective interaction of megalin with postsynaptic density-95 (PSD-95)-like membrane-associated guanylate kinase (MAGUK) proteins. Biochem J 373:381-391.

Lazarov O, Robinson J, Tang YP, Hairston IS, Korade-Mirnics Z, Lee VM, Hersh LB, Sapolsky RM, Mirnics K, Sisodia SS (2005) Environmental enrichment reduces abeta levels and amyloid deposition in transgenic mice. Cell 120:701-713.

Lee WH, Michels KM, Bondy CA (1993) Localization of insulin-like growth factor binding protein-2 messenger RNA during postnatal brain development: correlation with insulin-like growth factors I and II. Neuroscience 53:251-265.

Lopez-Lopez C, LeRoith D, Torres-Aleman I (2004) Insulin-like growth factor I is required for vessel remodeling in the adult brain. Proc Natl Acad Sci USA 101:9833-9838.

Morris R (1984) Developments of a water-maze procedure for studying spatial learning in the rat. J Neurosci Methods 11:47-60.

Morris SM, Tallquist MD, Rock CO, Cooper JA (2002) Dual roles for the Dab2 adaptor protein in embryonic development and kidney transport. EMBO J 21:1555-1564.

Niikura T, Hashimoto Y, Okamoto T, Abe Y, Yasukawa T, Kawasumi M, Hiraki T, Kita Y, Terashita K, Kouyama K, Nishimoto I (2001) Insulinlike growth factor I (IGF-I) protects cells from apoptosis by Alzheimer's V642I mutant amyloid precursor protein through IGF-I receptor in an IGF-binding protein-sensitive manner. J Neurosci 21:1902-1910.

Nunez A, Carro E, Torres-Aleman I (2003) Insulin-like growth factor I modifies electrophysiological properties of rat brain stem neurons. J Neurophysiol 89:3008-3017.

Obermuller N, Kranzlin B, Blum WF, Gretz N, Witzgall R (2001) An endocytosis defect as a possible cause of proteinuria in polycystic kidney disease. Am J Physiol Renal Physiol 280:F244-F253.

Oleinikov AV, Zhao J, Makker SP (2000) Cytosolic adaptor protein Dab2 is an intracellular ligand of endocytic receptor gp600/megalin. Biochem J 347:613-621.

Orlando RA, Rader K, Authier F, Yamazaki H, Posner BI, Bergeron JJ, Far- 
quhar MG (1998) Megalin is an endocytic receptor for insulin. J Am Soc Nephrol 9:1759-1766.

Pulford BE, Ishii DN (2001) Uptake of circulating insulin-like growth factors (IGFs) into cerebrospinal fluid appears to be independent of the IGF receptors as well as IGF-binding proteins. Endocrinology 142:213-220.

Sargiacomo M, Sudol M, Tang Z, Lisanti MP (1993) Signal transducing molecules and glycosyl-phosphatidylinositol-linked proteins form a caveolin-rich insoluble complex in MDCK cells. J Cell Biol 122:789-807.

Schlachetzki F, Zhang Y, Boado RJ, Pardridge WM (2004) Gene therapy of the brain: the trans-vascular approach. Neurology 62:1275-1281.

Schreiber G (2002) The evolution of transthyretin synthesis in the choroid plexus. Clin Chem Lab Med 40:1200-1210.

Schubert M, Brazil DP, Burks DJ, Kushner JA, Ye J, Flint CL, Farhang-Fallah J, Dikkes P, Warot XM, Rio C, Corfas G, White MF (2003) Insulin receptor substrate-2 deficiency impairs brain growth and promotes tau phosphorylation. J Neurosci 23:7084-7092.

Schubert M, Gautam D, Surjo D, Ueki K, Baudler S, Schubert D, Kondo T, Alber J, Galldiks N, Kustermann E, Arndt S, Jacobs AH, Krone W, Kahn CR, Bruning JC (2004) Role for neuronal insulin resistance in neurodegenerative diseases. Proc Natl Acad Sci USA 101:3100-3105.

Schwarzman AL, Gregori L, Vitek MP, Lyubski S, Strittmatter WJ, Enghilde JJ, Bhasin R, Silverman J, Weisgraber KH, Coyle PK (1994) Transthyretin sequesters amyloid beta protein and prevents amyloid formation. Proc Natl Acad Sci USA 91:8368-8372.

Sousa MM, Norden AG, Jacobsen C, Willnow TE, Christensen EI, Thakker RV, Verroust PJ, Moestrup SK, Saraiva MJ (2000) Evidence for the role of megalin in renal uptake of transthyretin. J Biol Chem 275:38176-38181.

Suzuki N, Cheung TT, Cai XD, Odaka A, Otvos Jr L, Eckman C, Golde TE, Younkin SG (1994) An increased percentage of long amyloid beta pro- tein secreted by familial amyloid beta protein precursor (beta APP717) mutants. Science 264:1336-1340.

Sytze VD, Aleman A (2004) Insulin-like growth factor-I, cognition and brain aging. Eur J Pharmacol 490:87-95.

Tanzi RE, Bertram L (2005) Twenty years of the Alzheimer's disease amyloid hypothesis: a genetic perspective. Cell 120:545-555.

Torres-Aleman I (2000) Serum growth factors and neuroprotective surveillance. Mol Neurobiol 21:153-160.

Trejo JL, Carro E, Torres-Aleman I (2001) Circulating insulin-like growth factor I mediates exercise-induced increases in the number of new neurons in the adult hippocampus. J Neurosci 21:1628-1634.

Trejo JL, Carro E, Nunez A, Torres-Aleman I (2002) Sedentary life impairs self-reparative processes in the brain: the role of serum insulin-like growth factor-I. Rev Neurosci 13:365-374.

Zerbinatti CV, Wozniak DF, Cirrito J, Cam JA, Osaka H, Bales KR, Zhuo M, Paul SM, Holtzman DM, Bu G (2004) Increased soluble amyloid-beta peptide and memory deficits in amyloid model mice overexpressing the low-density lipoprotein receptor-related protein. Proc Natl Acad Sci USA 101:1075-1080.

Zlokovic BV (2004) Clearing amyloid through the blood-brain barrier. J Neurochem 89:807-811.

Zlokovic BV, Martel CL, Matsubara E, McComb JG, Zheng G, McCluskey RT, Frangione B, Ghiso J (1996) Glycoprotein 330/megalin: probable role in receptor-mediated transport of apolipoprotein $\mathrm{J}$ alone and in a complex with Alzheimer disease amyloid beta at the blood-brain and blood-cerebrospinal fluid barriers. Proc Natl Acad Sci USA 93:4229-4234.

Zufferey R, Nagy D, Mandel RJ, Naldini L, Trono D (1997) Multiply attenuated lentiviral vector achieves efficient gene delivery in vivo. Nat Biotechnol 15:871-875. 